\title{
Análisis del precedente vinculante en materia tributaria en el Perú ${ }^{*}$
}

\author{
César Dávila Alvarado ${ }^{(*)}$ \\ Abogado por la Universidad de Piura. \\ Miembro del Instituto Peruano de Derecho Tributario.
}

SUMARIO:

I. Introducción.

II. Distinciones conceptuales.

1. Interpretación cognitiva vs. Interpretación decisoria.

2. Efectos inter partes y erga omnes.

3. Norma y metanorma.

4. Fuerza vinculante y fuerza justificativa.

4.1. Con relación a las reglas sobre fuerza vinculante.

4.2. Con relación a las reglas sobre la fuerza justificativa.

5. Ratio decidendi y obiter dicta.

5.1. Razón suficiente $y / 0$ necesaria.

5.2. Razón explícita e implícita.

5.3. Interpretando la ratio decidendi.

6. Justificación externa y justificación interna.

III. Interpretación de la regla del stare decisis en perú en materia tributaria.

1. Precedentes vinculantes de la Corte Suprema: principios jurisprudenciales.

1.1. ¿Qué precedentes vinculantes emite la Corte Suprema?

1.2. ¿En qué sentido son vinculantes?

1.3. ¿Qué parte es vinculante?

1.4. ¿A quiénes vincula?

2. Precedentes vinculantes del Tribunal Constitucional: jurisprudencia vinculante, precedente vinculante.

(*) Nota del Editor: La versión digital del presente artículo ha sido corregida luego de la publicación de la Edición $\mathrm{N}^{\circ} 40$ de $\boldsymbol{A D V O C A T U S}$, debido a un error del Editor, motivo por el cual difiere de la versión impresa. Entre otros ajustes menores, en la versión impresa, cuando en el artículo se hace referencia, erróneamente, al Código Procesal Civil, esta corresponde al Código Procesal Constitucional.

(*) El presente trabajo fue realizado, en gran medida, gracias al meticuloso cuidado y las atentas sugerencias de Fátima Moquillaza Robatty, alumna del noveno ciclo de la Facultad de Derecho de la Universidad de Lima. 


\title{
RESUMEN:
}

El presente trabajo tiene como objetivo realizar un análisis de diversos problemas prácticos a los que se enfrentan los operadores jurídicos cuando trabajan con precedentes, en especial, en materia tributaria. Las interrogantes que se tratará de analizar son: (i) ¿Cuáles de las interpretaciones realizadas por el Tribunal Constitucional y Corte Suprema son vinculantes? (ii) ¿En qué sentido son vinculantes? (iii) ¿En qué extensión son vinculantes? y, (iv) ¿a quiénes vinculan?

Se mostrará como el approach desde la filosofía analítica del derecho y sus distinciones conceptuales resulta fructífera para la tarea señalada.

Palabras clave: precedente vinculante, interpretación jurídica, inter partes, erga omnes, ratio decidendi, obiter dicta, Tribunal Constitucional, Corte Suprema.

\begin{abstract}
:
The present work aims to carry out an analysis of various practical problems that legal operators face when working with precedents, especially in tax matters. The questions to be analyzed are: (i) Which of the interpretations made by the Constitutional Court and the Supreme Court are binding? (ii) In what sense are they binding? (iii) To what extent are they binding? and, (iv) who do they link?

Keywords: binding precedent, legal interpretation, inter parts, erga omnes, ratio decidendi, obiter dicta, Constitutional Court, Supreme Court.
\end{abstract}

\section{INTRODUCCIÓN}

El objetivo principal del presente trabajo es determinar cuáles de las interpretaciones de los textos jurídicos ${ }^{1}$ - constitución, leyes, reglamentos, etc.- que realizan el Tribunal Constitucional y la Corte Suprema del Perú en materia tributaria son, en algún sentido, vinculantes.

Para dicho objetivo usaremos dos tipos de análisis. En primer lugar, nos valdremos de algunas distinciones conceptuales: interpretación cognitiva vs. interpretación decisoria, los efectos inter partes y erga omnes, norma y metanorma, ratio decidendi y obiter dicta, justificación externa e interna.

Segundo, tomaremos las definiciones arribadas en el plano conceptual, para verificar como han sido recogidas en nuestro derecho positivo o, siguiendo una línea más realista, en nuestro "derecho viviente"."

Finalmente, trataremos de analizar algunos problemas concretos: (i) cuales son las interpretaciones vinculantes de la Corte Suprema y el Tribunal Constitucional, (ii) en qué sentido son vinculantes, (iii) en qué extensión es vinculante, es decir qué parte de los textos que son considerados precedentes es vinculante y, (iv) cuál es su alcance institucional, es decir, quiénes se vinculan a aquellas interpretaciones.

\section{DISTINCIONES CONCEPTUALES}

Una primera aproximación conceptual al término "precedente" sería definirlo como el conjunto de las interpretaciones realizadas por los funcionarios públicos — de la Administración, Poder Judicial, Tribunal Constitucional, etc.-

1. Esta vez solo abarcaremos la vinculatoriedad de las decisiones interpretativas de textos jurídicos. Aunque, sin duda, es posible ampliar el alcance y analizar la vinculatoriedad de las decisiones sobre los hechos. En esta dirección puede revisarse el trabajo de Núñez Vaquero de 2018.

Por textos jurídicos entendemos el conjunto de documentos que contienen mensajes escritos que, en un contexto histórico dado - espacio, tiempo y lugar-, son considerados como portadores de normas jurídicas. Cfr. Tarello (1980), 38. Se podría utilizar como sinónimos: disposición o disposición jurídica o normativa, enunciado o enunciado jurídico o normativo.

2. Guastini usa ese término para referirse al derecho que es efectivamente aplicado por los órganos de aplicación: —administración, jueces, Tribunal Constitucional, entre otros- Guastini (2014), 353-354. 
que aplican el derecho y que, de alguna forma -aún por explicitar-, vinculan las decisiones de ellos mismos y otros funcionarios. ${ }^{3}$ Esta incipiente definición nos permitirá usar las siguientes distinciones que, de forma progresiva, irán precisando el concepto de precedente:

\section{Interpretación cognitiva vs interpreta- ción decisoria. ${ }^{4}$}

Se trata de una distinción por demás conocida:

a) Una cosa es explicitar el conjunto de interpretaciones o significados posibles o, dicho menos metafóricamente, el conjunto de normas que podrían derivar de los textos jurídicos ${ }^{5}$ en función a las reglas lingüísticas, técnicas argumentativas, o doctrinas jurídicas, etc.; b) otra, es elegir entre una de aquellas normas, descartando las demás.

Lo primero es un acto de cognición y es denominado interpretación cognitiva. Lo segundo una decisión y, por ello, es denominado interpretación decisoria.

Los precedentes se reconstruyen a partir de actos de aplicación del derecho en casos particulares. ${ }^{6}$ En aquellos casos, el aplicador debió decidir entre una de las varias normas posibles, es decir, realizó una interpretación decisoria. En ese sentido, podría afirmarse que un precedente es una interpretación decisoria —en sentido amplio-. ${ }^{8}$

\section{Efectos inter partes y erga omnes.}

Qué se entiende por vinculante será analizado

3. Para la misma aproximación véase, entre varios otros: Gascón Abellán y García Figueroa (2003), 207 y ss.; Taruffo M. (2016), 332; y, en el ámbito nacional Castillo Córdova (2008), 96-99.

Aun cuando sería conceptualmente posible, tratar con una definición de "precedente" que no incluya como propiedad "vinculatoriedad", una definición como ésa no sería útil para representar el uso común del término y su alcance sería tan amplio que no podría diferenciarse entre la jurisprudencia en general y los precedentes Tarruffo M. en 2016, por ejemplo, sugiere la importancia de esta distinción-.

4. Esta distinción forma parte de las lecciones propedéuticas del realismo de Guastini (2011), 45 y ss. en donde, luego de diferenciar entre disposición y la norma obtenida por interpretación, distingue distintas operaciones que usualmente son designadas bajo el término interpretación, a saber: interpretación cognitiva, decisoria, y creadora.

5. Vale decir, o de un fragmento de textos jurídicos, o un conjunto de dichos fragmentos, o de un conjunto de textos jurídicos, etc.

6. Con esto nos referimos a la solución de un caso particular, independientemente de si lo que se trate sea un juicio de la validez de un acto jurídico — público o privado - no normativo, o de uno, más bien, normativo — como sucede por ejemplo en los procesos de acción de inconstitucionalidad o acción popular-.

7. Veamos un caso de aplicación del derecho que es un buen candidato para ser considerando "precedente": El Decreto Legislativo 1113, vigente desde el 28 de setiembre de 2012, modificó las reglas de prescripción del Código Tributario, señalando que el plazo de prescripción de la acción de cobro iniciaría —obviamente, desde su entrada en vigencia-, con la notificación de las resoluciones de determinación. La estructura lógica de lo anterior, podría representarse como: "D significa N1".

Sin embargo, quedaba la "duda" de si dicha modificación, también expresaba que los plazos de prescripción ya iniciados, más bien "reiniciarían", con la notificación de las resoluciones de determinación. La estructura lógica de lo anterior, podría representarse como: "D significa N1 y N2".

La explicitación de ambos posibles resultados: (i) "D significa N1", (ii) "D significa N1 y N2", constituiría interpretación cognitiva. Decidir entre una de esas alternativas, sería interpretación decisoria.

En este caso, el Tribunal Constitucional, mediante Sentencia recaída en el Expediente №. 0004-2019-PI, realizó interpretación decisoria eligiendo la segunda alternativa (ii).

8. No se nos escapa el hecho que el precedente podría provenir no de una interpretación decisoria en sentido estricto, sino más bien estar precedida de una interpretación creadora o construcción normativa. 
a lo largo del presente trabajo. Sin embargo, aunque a primera vista parezca trivial, es importante realizar la siguiente precisión: la vinculación a la que se refiere la definición del término "precedente" es aquella que va más allá de la simple eficacia inter partes, la cual se predica del precedente, no de la sentencia o resolución que la pueda incorporar.

Nótese que no es conceptualmente necesario que se trate de una eficacia erga omnes o para todos - pues es posible pensar en precedentes con alcances más restringidos-, pero sí que la interpretación decisoria que constituye precedente pueda, al menos, contribuir en la decisión de otros casos. ${ }^{9}$

\section{Norma y metanorma. ${ }^{10}$}

También resultará útil distinguir entre:

a) Por un lado, el precedente como norma, es decir: la interpretación decisoria llevada a cabo en el caso particular, en otras palabras, la norma que resultó de aquella decisión interpretativa. b) Y, por otro, la metanorma del precedente, es decir: la norma o conjunto de ellas, que en un determinado ordenamiento jurídico establecen el régimen legal de la técnica del precedente. En el lenguaje común de los juristas, esta sería la regla del stare decisis.11

A su vez, la regla del stare decisis metanorma, puede ser entendida como una regulación dirigida: (i) al acto de producción del precedente, lo que constituiría un "régimen de producción del precedente", o (ii) al resultado del acto de producción, esto es, cómo el precedente - como normadebe incluirse en las decisiones jurisdiccionales $^{12}$ de los aplicadores del derecho: i.e., de los jueces y demás funcionarios públicos, lo que constituiría el "régimen legal de aplicación del precedente".

Por ello, esta metanorma podría contener cuando menos, las siguientes reglas ${ }^{13}$ :

(i) Una regla de producción, que comprendería,

Por medio de la interpretación creadora, los aplicadores suelen construir los siguientes resultados: (i) la existencia de una laguna axiológica; (ii) la formulación de normas implícitas, con el fin de (ii.1) colmar una laguna y/o de (ii.2) concretar un principio; (iii) la solución de una antinomia; (iii.1) incluidas las antinomias entre principios constitucionales que se solucionan mediante ponderación; (iv) la creación de jerarquías axiológicas entre normas —esta tipología la extraigo de Guastini (2011), 49 y ss.; y, 253 y ss.—.

No analizaremos a detalle este elemento para evitar complejizar más la cuestión. Sin embargo, dejemos establecido que en el supuesto que el precedente provenga de una interpretación creadora, ésta supone que, posteriormente, también se adscriba alguno de los significados "construidos" —ya no solo los "interpretados"—. De ahí que Guastini haya afirmado que "La única diferencia entre interpretación decisoria e interpretación creadora está no en la forma lógica de los enunciados a través de los cuales la una y la otra se expresan, sino en lo siguiente: que el significado adscrito al texto en un caso (interpretación decisoria estándar) se ubica entre aquellos identificados o identificables mediante interpretación cognitiva, en el otro caso (interpretación creadora) no."

En consecuencia, no existiría problema en afirmar que el precedente es una interpretación decisoria en sentido amplio: lo que incluye los casos de mera elección de los significados identificados por interpretación cognitiva -interpretación decisoria - y, los casos en donde luego de atribuir un nuevo significado se elige éste -interpretación creadora-.

9. La ausencia de esta precisión, ha generado algunos problemas de ambigüedad en tesis explicativas de reconocidos autores nacionales.

Sirva de ejemplo el caso del trabajo de Castillo Córdova (2008), el cual se dedica en buena parte al tema de la vinculatoriedad de las sentencias del Tribunal Constitucional. El referido profesor en sus textos sostiene que la definición de "vinculación" podrá: "tener efectos erga omnes (sentencia de inconstitucionalidad) o efectos inter partes (sentencias de amparo, habeas corpus, habeas data)" (2008), 101. Si eso es así puede interpretarse de su trabajo que las rationes decidendi: (i) pueden ser vinculantes, sólo para las partes, en cuyo caso no se ve la utilidad de usar el término "vinculante" para describir una situación como ésa, o (ii) pueden ser vinculantes para todos. De hecho, no se entiende muy bien 
(i.1) las reglas formales: que confieren competencia a un órgano específico y determinan el procedimiento.

(i.2) las reglas sustanciales: las que en el caso del precedente estarían referidas, fundamentalmente, a que éste sea "derivado" de los textos jurídicos.

Sin duda, estas reglas contribuyen a la definición del precedente, haciendo posible su identificación entre los distintos "fenómenos" jurídicos. ${ }^{14}$

(ii) Otra, que califique su uso institucional -i.e. permitido, obligatorio o prohibidoy su alcance institucional que usualmente es determinado según la posición organizacional del órgano que lo emite.

Por ejemplo, en el Perú, los precedentes emitidos por tribunales administrativos como el Tribunal Fiscal solo vinculan formalmente a los órganos administrativos, no así a la judicatura, mientras que los precedentes emitidos por la Corte Supre- ma y el Tribunal Constitucional tienen una vinculación formal mucho más amplia: los del primero no se duda que, al menos, a toda la judicatura $y$, los del segundo, respecto de los cuales los operadores no dudan que vincula a todo poder público y privado.

(iii) Otra, que establezca las acciones que implican emplear un precedente por parte de otro órgano - tales como: mencionar, tener en cuenta, aplicar, entre otros-.

(iv) Otra, sobre el contexto justificativo o "ubicación" en el proceso argumentativo, en el que sería eficaz — por ejemplo: podría estar ubicado al momento de la interpretación en abstracto definiendo el sentido de la norma, o interpretando en concreto el alcance de los predicados contenidos en una norma, entre otros-.

(v) Otra sobre la fuerza justificativa - es decir, si se trata de una razón concluyente, contribuyente o más bien meramente ilustrativa-y la fuerza vinculante. ${ }^{15}$

por qué el autor sostiene, inicialmente, que la rationes decidendi son vinculantes por el solo hecho de "ser tales" Castillo Córdova (2008), 101 y 128 para, luego, concluir que las no contenidas en un precedente vinculante "solo vinculan a las partes en el proceso" Castillo Córdova (2008), 129, es decir, con meros efectos inter partes.

Entonces, de lo anterior se seguiría más bien que: o las rationes decidendi, realmente, no son vinculantes por el hecho de "ser tales" - que parece una conclusión contraria a la idea central que el referido autor sostiene de manera reiterada a lo largo de su trabajo—, o son vinculantes en un sentido extraño en el contexto de la técnica del precedente, pues mantendrían simples efectos inter partes.

10. El término "metanorma", en "sentido amplio", comprende a toda norma que tenga por objeto no la conducta, sino: (a) actos normativos - “La función legislativa es ejercida de tal forma"—; (b) otras normas —-De acuerdo al principio de irretroactividad..."-; u (c) otras disposiciones. —“Queda derogado el artículo x de la ley y"—. Guastini (2016), 60 y ss.

11. En un sentido similar Núñez Vaquero (2016), 135 y ss.

12. En Sistemas Normativos (2017), Alchourrón y Bulygin (1975), 206, también se cuidan de utilizar el término decisiones "jurisdiccionales" para incluir a los funcionarios públicos, distintos de los jueces.

13. El contenido mínimo del precedente como metanorma que detallo es una reconstrucción de la propuesta de Núñez Vaquero (2016), 136 y ss.

14. Sobre cómo las normas de producción jurídica, a la vez, definen o contribuyen a la definición de la fuente del derecho sobre cuya producción se está regulando véase lo señalado por Guastini (2010), 69 y ss.

15. Un desarrollo de estas nociones, más adelante, en este mismo trabajo. 
Es posible afirmar que la regla (i) refiere al régimen de producción del precedente dirigida al acto jurisdiccional de producción, mientras que las reglas (ii) al (v) refieren al régimen de aplicación del precedente, dirigidas a cómo los aplicadores del derecho deben operar con el precedente resultante.

Es interesante mostrar, a su vez, que, en los ordenamientos jurídicos modernos, puede identificarse un régimen de las decisiones jurisdiccionales en general, compuesto por el siguiente conjunto de reglas ${ }^{16}$ :

(i) una que constituye la competencia para juzgar,

(ii) y otras que regulan cómo deben hacerlo. Lo que comprende los siguientes principios:

(ii.1) principio de inexcusabilidad, el juez no puede rechazarse a resolver.

(ii.2) principio de justificación, las decisiones judiciales deben estar justificadas - externa e internamente- $y$ de manera expresa.

(ii.3) principio de legalidad, la decisión se basa en normas jurídicas, que como veremos más adelante, implica disposiciones interpretadas: es decir, precedentes.

Lo anterior demostraría la siguiente relación circular: la producción del precedente, en tanto decisión jurisdiccional se rige por el régimen de la decisión jurisdiccional y, a su vez, la de- cisión jurisdiccional, en tanto comprende los principios de justificación y legalidad, se rige también por el régimen de aplicación del precedente. Bajo esta premisa, las decisiones jurisdiccionales deben "aplicar" el precedente —en el sentido y extensión que corresponda según cada ordenamiento-, pues de lo contrario podrían ser revocadas por incumplir el referido principio de justificación y/o legalidad.

La regla del stare decisis, entonces, es la que debería regular, tanto el sentido de la vinculación como su extensión - aunque, ciertamente, no es muy usual que las disposiciones jurídicas recojan un desarrollo al menos suficiente de estos aspectos, quedando en la mayoría de los casos a expensas de lo que vaya concretando la jurisprudencia-.

\section{Fuerza vinculante y fuerza justificativa.}

En un trabajo fundamental para la cultura jurídica moderna sobre los precedentes titulado Interpreting Precedents ${ }^{17}$, el denominado Círculo de Bielefeld ${ }^{18}$ nos entregó como una de sus conclusiones teóricas más importantes una completa clasificación acerca de los grados de vinculatoriedad - de mayor a menor-que los precedentes podrían tener en la práctica jurídica19:

(a) vinculación formal que, a su vez, podría ser:

(i) estricta,

(ii) derrotable, pero no derogable,

(iii) derrotable y derogable

(b) vinculación de facto, así como

(c) vinculación como fuerza justificatoria, y

(d) valor ilustrativo

16. Ratti (2013), 108 y ss.

17. MacCormick y Summers (1997).

18. Se trata de un grupo de académicos de altísimo nivel, entre ellos: Aarnio, Alexy, Laporta, MacCormick, Peczenik, Taruffo, Troper, Summers.

19. Véase MacCormick y Summers (1997), 463. 
Aun cuando dicha clasificación podría ser sometida a críticas ${ }^{20}$, nos parece útil pues refleja dos oposiciones que refieren a una parte del contenido de la regla del stare decisis. Así mientras que la regla sobre la fuerza vinculante, puede explicarse mediante las nociones de vinculación formal y de facto (a y b), la regla sobre la fuerza justificativa, puede explicarse con las nociones de vinculación como fuerza justificatoria y valor ilustrativo (c y d).

\subsection{Con relación a las reglas sobre fuerza vin- culante.}

Analicemos los tres niveles de vinculación formal, identificados en Interpreting Precedents:

\section{(a) Vinculación formal estricta}

Si en el ordenamiento jurídico la fuerza vinculante del precedente es estricta, aquel no es derrotable ni derogable. Esto quiere decir que los jueces deben aplicarlo siempre que se encuentren frente al mismo caso.

Ello no impide que el juez califique su caso como distinto del que versa el precedente $y$, en consecuencia, no aplicarlo a dicho caso. Es decir, incluso en la vinculación estricta el juez podría hacer distinguishing ${ }^{21}$ y desmarcarse del alcance del precedente, naturalmente, tendrá que motivar para ello.

(b) Vinculación formal derrotable, pero no derogable
En este grado de vinculación, el juez podría, a partir de consideraciones más relevantes, apartarse del precedente. El conjunto de las excepciones que podrían producir la derrota, puede estar más o menos definido - well-defined o not-weII-defined-.

El juez realizaría un razonamiento bastante similar o idéntico al de la derrotabilidad de normas en general. En donde, a pesar de existir una norma que prima facie resulta aplicable, el aplicador identifica alguna propiedad relevante que el legislador —en este caso: el órgano que estableció el precedente- no consideró, lo que generaría que la solución prevista por la norma sea considerada inadecuada por dicho aplicador, por lo que, el razonamiento concluirá que el caso ya no queda comprendido en el alcance de la norma -en este caso: el precedente-, creándose una laguna axiológica ${ }^{22}$, que es posteriormente colmada por el referido aplicador mediante la extensión o analogía de otra norma. También se produciría una derrota del precedente en caso el aplicador realizara una nueva evaluación o ponderación de los "valores" involucrados en él, determinando que existe una más "justa" o más "correcta" o más "conforme a derecho". Así las cosas, la derrota del precedente podría ocurrir: o por la creación de una laguna axiológica o, mediante una nueva ponderación de los criterios involucrados en aquel.

20. Y, de hecho, así ha ocurrido a partir de las observaciones realizadas por Chiassoni P. (2018), 253 y ss.; y, (2019), 213 y ss., en donde se recogen las ideas que trabajó en un artículo publicado en la Revista Analisi e Diritto en el 2004, con el título "Il precedente giudiziale:tre esercizi di disincanto".

21. Schauer (2009), 58, refleja esta idea de la siguiente forma:

"Although it might be said that a binding precedent from a higher court simply obliges the lower court to follow it, it would be more accurate to say that a binding precedent obliges a lower court to follow it or to distinguish it from the instant case. In practice, a great deal of legal argument involves the attempt by one side to claim that some higher court case controls the result in the instant case, while the other side insists that there is a sufficient distinction between the two that the outcome in the precedent case need not be the outcome in the instant case."

22. Cfr. Alchourrón y Bulygin (1975), 156 y la formulación de Atienza y Ruiz Manero (2000), 62.

En cualquier caso, queda claro que se trataría de un fenómeno distinto al de la laguna normativa, en donde, prima facie no existiría una solución aplicable al caso. 
Debe dejarse dicho, sin embargo, que los tribunales jerárquicamente inferiores son, en la mayoría de sistemas jurídicos, considerados como órganos sin la competencia para realizar este tipo de operaciones. ${ }^{23} \mathrm{Y}$, en el caso que, a pesar de ello, dichos tribunales derrotaran un precedente, es bastante común que los tribunales superiores revoquen esas decisiones. ${ }^{24}$

En el Perú, el conjunto de disposiciones normativas sobre los precedentes de la Corte Suprema en procesos contencioso administrativos, señala, por un lado, (i) que los órganos jurisdiccionales pueden "apartarse" en atención a "circunstancias particulares" 25 . Y, por otro, (ii) que la misma Corte Suprema puede "apartarse" siempre que haga "mención expresa del precedente que deja de ser obligatorio por el nuevo $^{\prime 26}$, en ambos casos naturalmente de manera debidamente motivada. Se trata de casos de apartamiento del precedente.

El término apartamiento, proviene del inglés "departures", que es una categoría que comprende a las operaciones de distinguishing, derrotabilidad y overruling, entre otras, que no son otra cosa que formas de apartamiento.

Teniendo en cuenta ello, es posible señalar que, (i) la primera disposición haría referencia más propiamente al distinguishing $y$, por ello, señala como motivo del apartamiento la atención a "circunstancias particulares", mientras que, (ii) la segunda disposición, se referiría a la técnica del overruling y, en esa medida, regula una potestad del mismo órgano que lo emitió, tal como es regulado en la mayoría de sistemas jurídicos, en donde aquella potestad es otorgada institucionalmente solo a los más altos tribunales. ${ }^{28}$ Precisamente, el Tribunal Constitucional peruano, aunque para el caso de los precedentes vinculantes que éste emite, ha señalado que, a diferencia del distinguishing que es usado por los tribunales inferiores, el overruling es una técnica del "propio Tribunal que lo ha establecido con efecto vinculante"29.

Asimismo, puede afirmarse que en los textos jurídicos emitidos por las autoridades normativas parece no haber referencia alguna a la operación de derrotabilidad de

23. MacCormick y Summers (1997), 524: "The lower courts - the trial courts of general jurisdiction - do not, in any of the systems in our study, appear to have the power to overrule or modify a precedent in anticipation that upper courts will agree. That is, the institutional act of voiding a precedent or of officially revising a precedent is simply not within their authority" - el subrayado es nuestro-.

24. Así lo reportan los autores por país en Interpreting Precedents. Sugiero revisar especialmente los reportes de los países del civil law y el capítulo 18.

25. Tercer párrafo del artículo VI del Título Preliminar del Código Procesal Constitucional.

26. Artículo 22 de la Ley Orgánica del Poder Judicial.

27. Al respecto, Cfr. MacCormick y Summers (1997) y, Schauer (2009).

28. MacCormick y Summers (1997), 529-530:

"On the other hand, nearly all countries in the study limit the power explicitly to overrule or modify, or the like, to the highest appellate court or intermediate appellate court of the system having jurisdiction over the matter. Intermediate appellate courts may not anticipatorily overrule precedents of the highest court."

29. Sentencia recaída en el expediente № 3361-2004-AA/TC: "De este modo, aun en los sistemas donde el precedente es la fuente principal de organización de su sistema jurídico, se han previsto mecanismos no sólo para 'evadir' sus efectos mediante la técnica del distinguishing en el caso de los tribunales inferiores; sino incluso para 'cambiarlo' por un nuevo precedente, en el caso del propio Tribunal que lo ha establecido con efecto vinculante." 
los precedentes, ya sea que se realice mediante argumentos dirigidos a identificar una supuesta propiedad no evaluada por el tribunal que estableció el precedente, o la evaluación de las razones - y valores involucrados- en dicho precedente.

(c) Vinculación formal derrotable y derogable

Este sería el caso de menor "vinculación formal" del precedente. Aquí los jueces pueden ya no solo hacer distinguishing, o inaplicar el precedente al caso concreto luego de haberlo derrotado, sino derogarlo o modificarlo: hacer overruling.

Sin embargo, tal como hemos adelantado el overruling, en casi la totalidad de sistemas jurídicos, es una competencia otorgada al tribunal que establece el precedente o a los más altos tribunales.

A la vinculación formal suele oponerse la vinculación de facto, entendida esa última como la fuerza persuasiva que produce en los destinatarios. Sin embargo, no se trata de conceptos excluyentes, sino que pueden relacionarse perfectamente. De hecho, el precedente podría, según el ordenamiento jurídico analizado, (i) deber ser vinculante formalmente y ser persuasivo, (ii) deber ser vinculante formalmente $y$ no ser persuasivo, (iii) no deber ser vinculante formalmente y ser persuasivo, (iv) no deber ser vinculante formalmente y no ser persuasivo.

Esto demostraría que la vinculación formal y de facto, no son grados o niveles de vinculatoriedad, sino que tratan la vinculatoriedad en distintos planos, uno se refiere al régimen jurídico del stare decisis y, el otro a lo que en los hechos ocurre.

\subsection{Con relación a las reglas sobre fuerza jus- tificativa.}

Aquí son relevantes las nociones de vinculatoriedad como fuerza justificatoria y la meramente ilustrativa. Nos parece, otra vez, que aquellas no hacen exacta referencia a "grados" de vinculatoriedad del precedente como los presenta el Círculo de Bielefeld, sino dos momentos del razonamiento jurídico en los que podría operar la vinculación, entendida en este sentido.

Se afirma que dentro del razonamiento jurídico que sustenta las decisiones jurisdiccionales, puede distinguirse el contexto del descubrimiento y el contexto de la justificación. El primero sería la forma psicológica, causal, como el juzgador llega a una decisión. El segundo en cambio, sería la labor de justificar porqué se ha tomado dicha decisión. ${ }^{30}$ "Una cosa son los motivos de una decisión, otra cosa son las razones que la sustentan". ${ }^{31}$

Creemos que el precedente como meramente "ilustrativo" en realidad estaría haciendo referencia a un motivo que interviene en el proceso heurístico en el que se toma una decisión, mientras que al considerarlo con fuerza "justificatoria", se estaría haciendo referencia a los esfuerzos de motivación de las decisiones judiciales, de proporcionar razones - jurídicas-, de porqué se decidió entre una de las varias soluciones posibles.

\section{Ratio decidendi y obiter dicta.}

Aun superado el tema de qué se entiende por "vinculatoriedad", queda responder en qué extensión se entendería vinculante un precedente o qué parte de éste es vinculante.

30. Véase lo fructífero de dicha distinción en el clásico trabajo de Taruffo, La Motivación de la Sentencia Civil (1975), pues partir de ella, lo divide, para analizar por un lado la "lógica del juicio" y, por otro, la "lógica de la motivación". Esta distinción también es utilizada con bastante provecho por Comanducci en su Razonamiento Jurídico. Elementos para un modelo (1999). Esta distinción ha llevado a los estudios modernos a concentrar el análisis en el contexto de la justificación, pues lo que importa no es cual haya sido el proceso psicológico del decisor o cuales sean sus verdaderas intenciones, sino si dicha decisión está justificada conforme al principio de legalidad. Sin embargo, Cfr. Redondo (2009).

31. Guastini (2011), 233. 
La respuesta usual de los juristas es que es vinculante la "ratio decidendi". Pero el término ratio decidendi tiene múltiples significados, por lo que no termina siendo suficientemente útil o explicativo si con él se pretende otorgar un criterio "seguro" para determinar qué parte del precedente es vinculante. Por ejemplo, Chiasson $^{32}$ ha identificado once nociones de ratio decidendi distintas y, cada una de ellas, indeterminadas en algún sentido.

Una noción bastante generalizada en el lenguaje de los juristas, es la que define a la ratio decidendi como la razón, máxima, principio, regla, norma, que puede ser necesaria y/o suficiente para arribar a la decisión del caso; mientras que, por oposición, obiter dicta sería todo aquello que no queda comprendido como ratio.

Sin embargo, dicha noción dejaría abiertas, cuando menos, las siguientes interrogantes:

a) ¿Se trata de una razón suficiente, o necesaria, o suficiente y necesaria? ${ }^{33}$ b) ¿Se trata de una razón explícita o implícita?

c) ¿Se trata de las razones que el juez intencionalmente —subjetivamente- pretendía establecer como ratio, o las que independientemente de ello -objetivamente- se implican del texto de la decisión jurisdiccional?

d) ¿Se trata de las razones "correctas" — conforme a determinada técnica interpretativa, dogmática, etc.- o, independientemente de ello, las establecidas como ratio?

De hecho, en la doctrina nacional puede evidenciarse cómo la noción de ratio decidendi oscila alrededor de dichas interrogantes. En este trabajo, por cuestiones de extensión, analizaremos solo las dos primeras.

\subsection{Razón suficiente y/o necesaria.}

Según Castillo Córdova ${ }^{36}$, quien prudentemente se remite a las definiciones realizadas por el Tribunal Constitucional peruano, la ratio decidendi debe ser entendida como "la base de la

32. Chiassoni P. (2018), 266.

33. Pese a las evidentes distinciones de la estructura lógica entre razones suficientes — que por sí solas explican una conclusión-, o las necesarias — aquellas que no lo hacen por sí solas pero que es imprescindible que concurran-, o las suficientes y necesarias — las que "si y solo si" concurren explican la conclusión—; la dogmática suele utilizar estos términos de manera más metafórica que precisa.

Véase, por ejemplo, Castillo Córdova (2008), 111, cuando trata sobre lo que en su trabajo denomina "base objetiva" para diferenciar la ratio del obiter: "Si la relación es necesaria, de modo que el fallo hubiese tenido otro contenido y sentido si faltase esa razón o fundamento, entonces la razón es una razón suficiente o ratio decidendi." Se evidencia que los términos son utilizados de manera indistinta, quedando privados de utilidad explicativa.

34. De acuerdo con Grández Castro (2007), 99 parecería inclinarse por la "corrección" como elemento definitorio del precedente. No obstante, no brinda mayor explicación sobre qué parámetros o criterios de corrección aplicaría.

35. En este apartado, analizaremos los ejemplares trabajos de Castillo Córdova en 2008 y Grández Castro en 2007 acerca del precedente en materia constitucional.

Ambos trabajos constituyen una excelente demostración de aquellos en donde el lenguaje descriptivo y prescriptivo se sintetiza de manera que no es posible, posteriormente, separar que función se estaría realizando en uno u otro pasaje. A ese respecto, véase como Castillo Córdova a partir de lo que presenta como una descripción acerca de lo que la ratio decidendi es, señala que esa constatación es razón suficiente para concluir "pacíficamente" que debe ser vinculante Castillo Córdova (2008), 10. O como Grández Castro, quien luego de poner en evidencia la vinculación "necesaria" entre la ratio decidendi y el caso, señala que, por esa razón, aquellos textos que sean anunciados formalmente como ratio decidendi, pero que materialmente no lo sean, no vinculan. En ambos casos se trata de conclusiones normativas, extraídas a partir de meras descripciones conceptuales, sin remitirse, al menos no directamente, a los textos jurídicos de las autoridades normativas.

36. Castillo Córdova (2008), 100. 
decisión", "la consideración determinante para la decisión", "la regla indispensable y justificante para resolver la litis". Como expresa Grández Castro $^{37}$, estas nociones constituyen "límites (que) apuntan, básicamente, a la necesidad de vincular la regla del precedente con el caso decidido por Tribunal". Lamentablemente, estas paráfrasis utilizadas como definiciones son tan amplias que se tornan inoperantes para los aplicadores jurídicos —o bien, nos les permite hacer nada, o bien se les permite hacer todo con ellas-.

Veamos el siguiente ejemplo. Imaginemos que la Corte Suprema decidió para un caso particular, que no aplican intereses moratorios respecto de pagos a cuenta del Impuesto a la Renta Anual en el supuesto que se modifiquen los elementos establecidos por ley para su cálculo, luego de la oportunidad en que surge su obligación. Para ello, no obstante, dicha Corte, en el ejemplo planteado, realiza interpretaciones decisorias sobre varias cuestiones "necesarias" para su conclusión: por ejemplo, (i) sobre la extensión de las causales de casación invocadas por el recurrente -independientemente de su fundabilidad o no-, (ii) sobre los elementos definitorios de un tributo, excluyendo como tal la propiedad de poder ser usado como crédito por el contribuyente, por lo que, en tanto el pago a cuenta es usado como crédito contra el Impuesto a la Renta Anual, no calificaría como un tributo, (iii) sobre la forma correcta, o conforme a ley, de determinar los pagos a cuenta, (iv) sobre la extensión de la regla de intereses moratorios, (v) sobre las reglas generales de interpretación de las normas tributarias. Así, además, la Corte Suprema del ejemplo, aprovecha el caso para establecer explícitamente como precedente vinculante que "la interpretación de las normas tributarias debe realizarse no extensivamente respecto de normas que establecen obligaciones, ni de forma restrictiva respecto de normas que establecen derechos" -que sería una formulación más fina de (e)-.

Como puede evidenciarse, todas las razones anteriores serían "necesarias" para la solución dada por la Corte Suprema. Un aplicador que tuviera que decidir cuál es la ratio decidendi de la sentencia de la Corte Suprema, haciendo sólo uso de la noción de "necesidad"38, (i) o no podría elegir entre cualquiera de ellas, en tanto todas serían igualmente necesarias, (ii) o bien, elegir cualquiera de ellas por la misma razón, naturalmente, operando con alguna preferencia respecto alguna de ellas, sin explicitarlo.

Además, si en el ordenamiento jurídico del ejemplo, como ocurre en el Perú, existiera alguna disposición o norma que establezca que "son vinculantes las razones explícitamente establecidas como tales", y otra disposición o norma que señale que "son vinculantes las rationes decidendi establecidas por tal órgano que cumplan con el criterio de necesidad", el aplicador tendría otro problema más, pues se vería en la disyuntiva de considerar como ratio vinculante: (i) o solo la explícitamente establecidas, o (ii) las explícitamente establecidas junto con las que sin serlo, igual constituyan ratio decidendi por ser "necesarias" para la decisión.

\subsection{Razón explícita e implícita.}

En esa misma línea, que la ratio decidendi oscila entre razones explícitas o implícitas puede mostrarse en el hecho cómo la dogmática constitucional peruana ${ }^{39}$, diferencia entre la "jurisprudencia constitucional vinculante o doctrina jurisprudencial" y el "precedente vinculante constitucional", definiendo la primera como las tendencias de solución o decisiones interpretativas reiteradas realizadas por el máximo tribunal en materia constitucional

37. Grández Castro (2007), 101.

38. O, cualquiera de sus enésimas formulaciones: "la base de la decisión", "la consideración determinante para la decisión", "la regla indispensable y justificante para resolver la litis". 
-i.e. el Tribunal Constitucional peruano- a las que se refería el tercer párrafo del artículo VI del Código Procesal Constituciona ${ }^{40}$ peruano y, lo segundo, a la ratio explícitamente establecida como precedente vinculante por aquel tribunal, supuesto al que se referiría el artículo VII del Código Procesal Constitucional. ${ }^{41}$

\subsection{Interpretando la ratio decidendi.}

Si entiendo bien, la propuesta dogmática antes señalada se dirigiría a afirmar que ambas nociones, jurisprudencia constitucional vinculante y precedente vinculante, son "vinculantes", no obstante, en el primero corresponde a los aplicadores identificar qué parte es vinculante, es decir, la ratio decidendi implícita y, en el segundo el Tribunal Constitucional señala directamente qué parte es la vinculante, esto es, la ratio decidendi explícita.

Si esto es así, no se comprende como a partir de dicha premisa se podría concluir: (i) que la ratio decidendi explícita tiene por sí sola "nivel de norma constitucional", (ii) o que solo el Tribunal
Constitucional sea el único que pueda variar su "contenido normativo", como concluye Grández Castro. ${ }^{42}$

La primera de las conclusiones, no es la que nos interesa tratar, así que basta con dejar establecido que aquella sólo podría ser válida en la parte del precedente vinculante que interprete una disposición constitucional, pero no tendría por qué ser así si se tratara de una interpretación de una ley o, más aún, de un reglamento.

La segunda sería una proposición más interesante para nuestros fines. Se trataría de una proposición que no logra captar la forma como los operadores jurídicos realmente aplican la ratio decidendi explícita, esto es, previa interpretación del precedente..$^{43}$ Es decir, incluso una ratio decidendi explícita, para ser aplicada es -no pueden no ser- sometida a interpretación. Lo anterior, por la sencilla razón que todos los textos jurídicos -incluidos los precedentes vinculantes - no son entidades auto-interpretativas - self-interpreting en-

40. Código Procesal Constitucional:

"Artículo VI.- Control Difuso e Interpretación Constitucional

(...)

Los Jueces interpretan y aplican las leyes o toda norma con rango de ley y los reglamentos según los preceptos y principios constitucionales, conforme a la interpretación de los mismos que resulte de las resoluciones dictadas por el Tribunal Constitucional."

41. Código Procesal Constitucional:

"Artículo VII.- Precedente

Las sentencias del Tribunal Constitucional que adquieren la autoridad de cosa juzgada constituyen precedente vinculante cuando así lo exprese la sentencia, precisando el extremo de su efecto normativo. Cuando el Tribunal Constitucional resuelva apartándose del precedente, debe expresar los fundamentos de hecho y de derecho que sustentan la sentencia y las razones por las cuales se aparta del precedente.

(...)"

42. Grández Castro (2007), 96.

43. Lo que Tarello y La interpretación de la Ley (2013), (1980), 38-39, llamaría "interpretación de la jurisprudencia": "Las atribuciones de significado a documentos, que por brevedad llamamos normativos, pueden concretarse a su vez — y ello es habitual — en documentos susceptibles de ulterior interpretación. Los documentos de segundo grado se consideran dotados de fuerza normativa mayor o menor según la posición institucional de sus autores14. Según la fuerza normativa de los documentos de segundo grado, y según las concepciones jurídicas de que se parte, se tiende a incluir en el área semántica de «interpretación de la ley» también a la interpretación de tales documentos normativos de segundo grado. En cambio, cuando es necesario, u oportuno o deseable distinguir, se contraponen a la «interpretación de la ley», de ocasión en ocasión, la «interpretación de la jurisprudencia», la «interpretación de la práctica administrativa», la «interpretación de los dictámenes del Consejo de Estado», y así en adelante." 
tities $-{ }^{44} \mathrm{y}$, dado que no son autosuficientes antes de ser aplicados requieren ser refinados o reformulados para ser útiles para el aplicador en el caso concreto. Sólo si se acepta la tesis de la "claridad o sencillez" de los enunciados jurídicos, podría sostenerse que, al menos aquellos que tengan dichas propiedades, no requieren interpretación. Pero esa tesis, hoy en día es muy difícil de mantener en el plano teórico ${ }^{45}$ y más aún en los hechos, pues es fácil constatar cómo en los distintos ordenamientos jurídicos que cuentan con un sistema de precedentes, existen discrepancias al momento de su aplicación referidas, por lo menos, a qué parte es vinculante. $Y$ resuelto lo anterior, ¿qué expresa el precedente vinculante, esto es, cual es la premisa normativa que establece?

Haciendo uso de las categorías recién analizadas, podría afirmarse que se interpreta un precedente cuando: (i) se interpreta el texto de la sentencia, para extraer la ratio decidendi implícita ${ }^{46}$, o (ii) se interpreta el texto de la ratio decidendi implícita obtenida, o la ratio decidendi explicita, para en ambos casos extraer el argu- mento o la premisa normativa que se incluiría en el razonamiento jurídico del aplicador. ${ }^{47}$

Puede conjeturarse que la ausencia de este tipo de operaciones de interpretación de los precedentes en la reconstrucción conceptual realizada por el profesor Grández Castro, es lo que le llevaría a afirmar que "tiene pleno sentido, también en nuestro entorno, el saber diferenciar entre el obiter y la ratio en una decisión, de modo que lo que a todas luces es un obiter, no puede constituir la regla vinculante que el Tribunal anuncie" ${ }^{48}$. Esa afirmación podría resultar engañosa pues implicaría que los precedentes serían enunciados jurídicos "claros" en los que es suficiente una sucesión de actos de conocimiento - "saber diferenciar"-, para identificar la ratio y el obiter dicta y, no pone en relieve la necesaria labor interpretativa del precedente que realizan los operadores jurídicos. Labor para la cual, se ha podido evidenciar, los conceptos de "necesidad" y sus paráfrasis, se han revelado insuficientes.

\section{Justificación externa y justificación interna.}

Es aceptado de manera generalizada que un

44. Extraemos el término de Chiassoni P. (2019), 2. Sin embargo, la idea de la falta de autosuficiencia de los textos jurídicos fue fuertemente resaltada desde Tarello, como parte de sus objetivos "desmitificadores" del pensamiento jurídico -Cfr. Tarello (1980), Capitulo I.4.-.

45. Ratti (2013), 179: "como advierte SULLIVAN (1999) el «significado literal» o «significado evidente» (plain meaning) son a menudo términos vacíos, usados, por los juristas para simular haber encontrado un significado objetivo incontrovertible (determinado por reglas semánticas), cuando de hecho han elegido el significado a atribuir a un texto. La presunta sencillez de los casos claros, en efecto, depende por lo menos de cuatro factores, correlacionados con el supuesto «significado evidente» de una fuente jurídica: 1) la elección del texto a interpretar; 2) la elección del co-texto en cuyo alcance el texto es leído; 3) el mismo sentido de "significado literal o evidente», entendido en sentidos diferentes, y a veces hasta incompatibles; y 4) el contexto social e histórico en el que el texto es leído". Agrega que, a decir de Sullivan, respecto de los términos "literal o evidente": "is also clear that different judges mean different things by them. This ever-shifting terminology is a shell game". En buena cuenta, afirmar que los textos tienen un "significado evidente", es sólo un argumento para soportar una determinada interpretación, y no permite ningún control inter subjetivo, es un shell game.

De hecho, aún en el hipotético - y por demás muy poco probable - caso, que se presente al aplicador un enunciado jurídico respecto del cual existe un acuerdo en la comunidad jurídica relevante acerca de todos los factores señalados, no podrá negarse que opera una elección - precisamente, la que decide por el significado generalmente aceptado - y, en ese sentido, una interpretación decisoria. Véase Comanducci (2016), 73.

46. Este sentido de interpretación es al que se refiere en Interpreting Precedents.

47. Y, este sentido, al que se refiere en Chiassoni P. (2019), 209 y ss.

48. Grández Castro (2007),106. 
modelo de decisión jurisdiccional correcto, es aquel que está justificado racionalmente. Esto significa que se cumpla con las exigencias de justificación interna y externa: ${ }^{49,50}$

\section{a) Justificación interna:}

Implica que la decisión se infiera lógicamente de sus premisas - normativas y fácticas-. Usualmente, es entendido como una exigencia de racionalidad formal, que puede ser representada a través de la idea del principio de no contradicción. La estructura podría representarse como sigue:

(i) Premisa normativa - norma-, que es la regla general producto de una interpretación decisoria de alguna disposición normativa, o también, fruto de alguna interpretación creadora o construcción jurídica - por ejemplo: la regla por la cual "los sujetos que generan rentas empresariales, determinada conforme a ciertas reglas, deben tributar el Impuesto a la Renta Corporativo"-

(ii) Premisa fáctica, que describe los hechos luego de comprobaciones empíricas, es decir, mediante las pruebas —en el ejemplo: "se ha probado que la empresa $A$ ha generado utilidades operativas"-.

(iii) La subsunción genérica por la cual se interpreta -en concreto- que el enunciado de la premisa fáctica está comprendido en el alcance de la premisa normativa —en el ejemplo:
"Generar utilidades operativas califica como rentas empresariales" -

Y una subsunción individual por la cual se afirma que el caso concreto queda comprendido en el alcance de la premisa normativa en el ejemplo: "la empresa A ha generado rentas empresariales"

(v) La decisión que, usualmente, es el mandato individual y concreto, que deriva de las premisas -en el ejemplo: "La empresa A debe tributar el Impuesto a la Renta Corporativo-.

b) Justificación externa:

Que refiere a la solidez — soundness- de las premisas - normativas y fácticas- utilizadas en la justificación interna. Esta exigencia es más bien de racionalidad sustancial que puede representarse mediante la idea del principio de razón suficiente.

En este nivel, operan (i) los distintos argumentos destinados a sustentar, la premisa normativa que es utilizada en la justificación interna, ya sea mediante argumentos "interpretativos" — por ejemplo: utilizando el argumento literal para preferir una determinada interpretación- o "constructivos"51 — por ejemplo: utilizando la ponderación para establecer alguna jerarquía entre principios enfrentados-, según sea el resultado.

Así como, (ii) aquellos destinados a sustentar la premisa fáctica, que en muy apretado resumen implica elegir la hipótesis fáctica que mediante una valoración racional

49. Sobre la justificación interna y externa como justificación de la decisión jurisdiccional véase el ensayo pionero de Wróblewsky en 1974. Asimismo, los desarrollos de Chiassoni P. de 2007 y de Guastini de 2011.

50. Nuestro Tribunal Constitucional lo ha recogido en reiteradas oportunidades, entre ellas en las sentencias recaídas en los expedientes $N^{\circ}$ 3943-2006-PA/TC y 0896-2009-PHC/TC.

51. Sobre cómo operan los referidos argumentos, nos remitimos a Guastini en 2011. 
del acervo probatorio incluido válidamente en el procedimiento supera el estándar probatorio exigido para cada caso. ${ }^{52}$

Pues bien, el precedente como norma, bien podría estar ubicado:

(i) a nivel de la justificación interna: si refiere a un resultado interpretativo que puede ser usado como premisa normativa o que realiza una subsunción; o

(ii) a nivel de la justificación externa: pues podría referirse a un argumento interpretativo o constructivo, antes que a una regla general o enunciado subsuntivo directamente utilizables como premisas en la justificación interna.

Teniendo en cuenta todas las distinciones conceptuales desarrolladas, el conjunto de interpretaciones vinculantes podría comprender cualquier interpretación decisoria contenida en una decisión jurisdiccional que vincule a los órganos de aplicación jurídica -administrativos o judiciales - en alguno de los sentidos analizados: formalmente -en el sentido, extensión y alcance institucional según cada ordenamiento jurídico- o de facto, y, que, por ello, es considerada con fuerza justificativa en el contexto de la motivación de las decisiones judiciales, la cual podrá referirse y, por ello ser incluida, tanto a nivel de la justificación interna o externa de aquellas decisiones.

Además, por lo general, se entiende que la parte vinculante del precedente es la denominada ratio decidendi que generalmente es definida como la razón necesaria y/o suficiente para la decisión. Sin embargo, no puede dejarse de observar que aquellos criterios de identificación no han sido aún suficientemente especificados a nivel dogmático y jurisprudencial, por lo que podrían resultar inoperantes; y que, finalmente, la determinación de qué parte es ratio deciden- di y, más aún, de cuál es la razón o norma contenida en aquella, son operaciones fundamentalmente interpretativas.

\section{INTERPRETACIÓN DE LA REGLA DEL STARE DECISIS EN PERÚ EN MATERIA TRIBUTARIA}

En materia tributaria, la regla del stare decisis podría reconstruirse, fundamentalmente, a partir del artículo 36 de la Ley del Procedimiento Contencioso Administrativo, el artículo 22 de la Ley Orgánica del Poder Judicial y el tercer párrafo del artículo VI y artículo VII del Código Procesal Constitucional, que regulan los precedentes de la Corte Suprema y el Tribunal Constitucional.

Sin duda, también podría considerarse precedente vinculante, por ejemplo, la jurisprudencia de observancia obligatoria del Tribunal Fiscal, pero dada la mayor importancia institucional de los precedentes emitidos por la Corte Suprema y el Tribunal Constitucional, así como la evidente superior jerarquía de estos tribunales de vértice, frente a los tribunales administrativos, restringiremos el análisis sólo a aquellos.

A continuación, analizaremos aquellos textos jurídicos y sus interpretaciones, en donde se demostrará que todas las distinciones e interrogantes que se planteaban a nivel conceptual, están presentes en el sistema jurídico peruano:

\section{Precedentes vinculantes de la Corte Su- prema: principios jurisprudenciales.}

\section{1. ¿Qué precedentes vinculantes emite la Corte Suprema?}

Veamos, el actual artículo 36 de la Ley del Procedimiento Contencioso Administrativo, modificado por el Decreto Legislativo 1067, señala:

"Artículo 36.- Principios jurisprudenciales. Cuando la Sala Constitucional y Social de la Corte Suprema fije en sus resoluciones prin-

52. Sobre el tema de la actividad probatoria, en especial sobre el esquema de valoración racional sugiero remitirse a Ferrer Beltrán en 2007 y, para la noción de estándar probatorio Ferrer Beltrán (2018). 
cipios jurisprudenciales en materia contencioso administrativa, constituyen precedente vinculante.

Los órganos jurisdiccionales podrán apartarse de lo establecido en el precedente vinculante, siempre que se presenten circunstancias particulares en el caso que conocen y que motiven debidamente las razones por las cuales se apartan del precedente.

El texto íntegro de todas las sentencias expedidas por la Sala Constitucional y Social de la Corte Suprema de Justicia de la República se publicará en el Diario Oficial El Peruano y en la página web del Poder Judicial. La publicación se hace dentro de los sesenta días de expedidas, bajo responsabilidad. (...)" 53
La disposición señala que constituye precedente vinculante los principios jurisprudenciales "fijados" por la Sala Constitucional y Social de la Corte Suprema. De una revisión de los precedentes emitidos en base a esta normativa, considero que, para nuestro sistema jurídico, puede concluirse que los términos "principios jurisprudenciales" y "precedente vinculante", son coextensionales, es decir designan el mismo conjunto, en este caso, de decisiones de la Corte Suprema. Ello pues en casi la totalidad de los casos, en donde la Sala Constitucional y Social de la Corte Suprema ha designado expresamente que un pasaje de su resolución constituye un "principio jurisprudencial", en la misma resolución, lo ha señalado también expresamente como "precedente vinculante". ${ }^{54,55}$

53. Antes de la modificatoria efectuada por el Decreto Legislativo 1067, publicado el 28 de junio de 2008, la disposición señalaba:

"Artículo 34.- Doctrina jurisprudencial

Las decisiones adoptadas en casación por la Sala Constitucional y Social de la Corte Suprema de Justicia de la República constituirán doctrina jurisprudencial en materia contencioso administrativa.

Los órganos jurisdiccionales inferiores podrán apartarse de lo establecido por la doctrina jurisprudencial, siempre que se presenten circunstancias particulares en el caso que conocen y que motiven debidamente las razones por las cuales se apartan de la doctrina jurisprudencial.

El texto íntegro de todas las sentencias expedidas por la Sala Constitucional y Social de la Corte Suprema de Justicia de la República se publicarán en el Diario Oficial El Peruano. La publicación se hace dentro de los sesenta días de expedidas, bajo responsabilidad."

De acuerdo a la exposición de motivos de dicho decreto ello fue así pues: "Una de las deficiencias actuales del proceso contencioso es la virtual clandestinidad de los pronunciamientos judiciales sobre la legalidad de la actuación de la administración pública. Con el objeto de provocar la mayor difusión de la jurisprudencia existente derivada de procesos contenciosos administrativos, se modifica del artículo $34^{\circ}$ vigente, con el objeto de precisar que cuando la Sala Constitucional y Social de la Corte Suprema fije en sus resoluciones principios jurisprudenciales en materia contencioso administrativa, constituyen precedente vinculante."

La modificatoria parece atacar dos puntos específicos: (i) se cambia el término "doctrina jurisprudencial" por "precedente vinculante", se puede conjeturar, para darle mayor institucionalidad, y, (ii) se señala que ello será así cuando el tribunal "fije" en sus resoluciones "principios jurisprudenciales".

54. Esto puede verificarse de una revisión de la sección "Ejecutorias Vinculantes" en la página web "Jurisprudencia Nacional Sistematizada": https://jurisprudencia.pj.gob.pe/jurisprudenciaweb/faces/page/inicio.xhtml

Naturalmente, si se definiera estipulativamente el término "principio jurisprudencial" como el conjunto de las rationes decidendi o de las interpretaciones decisorias de la Corte Suprema, podría afirmarse que podrían existir "principios jurisprudenciales" - explícitos o implícitos, según hemos analizado en la parte conceptual de este trabajo- que vinculan, a pesar de no ser declarados expresamente también "precedentes vinculantes" — de hecho, esa forma de entenderlo, tendría sentido con la disposición que exige la publicación de todas las sentencias pues ¿cuál sería la utilidad de que se publiquen todas sino para que vinculen de alguna forma?-. Sin embargo, esa no es la forma como ha sido usado/aplicado el término en la gran mayoría de casos por la Corte Suprema.

55. La excepción más resaltante es, precisamente, el conocido caso de la Casación N 4293-2013-Lima. En donde la Corte Suprema señala un "precedente vinculante", sin señalar que se trate también de un "principio jurisprudencial". Pero, sin duda, este es un caso aislado. 


\section{2. ¿En qué sentido son vinculantes?}

Naturalmente, la disposición citada estaría haciendo referencia a una vinculación institucional de los principios jurisprudenciales o precedentes vinculantes —en adelante, "PrJ"-, es decir, en sentido formal. Ello, sin perjuicio del nivel de vinculación de facto, es decir, de cuanta persuasión efectivamente generen.

Tal como hemos analizado antes, podría dudarse acerca de las formas de apartamiento que la regla del stare decisis en Perú admite respecto de los PrJ. La interrogante es isi los tribunales inferiores tienen la potestad de derrotar el PrJ?

De hecho, de la disposición que señala que los órganos jurisdiccionales pueden apartarse atendiendo a "circunstancias particulares", podría interpretarse que ello implica:

a) sólo aplicando el distinguishing, a partir de las diferencias entre el caso del precedente y el caso concreto,

b) o, apartándose, atendiendo a cualquier circunstancia particular, ya sea una supuesta propiedad relevante no atendida por la Corte Suprema, o realizando una completa nueva ponderación, para derrotar el precedente.

Vale adelantar que, en la dogmática y jurispru- dencia peruana, no conocemos de algún caso en donde esa interrogante haya sido plantea$\mathrm{da}$, al menos en esos términos. Es decir, si los tribunales inferiores pueden "derrotar" el PrJ. En cambio, lo que sí hemos podido identificar es más bien un argumento que se refiere muy genéricamente $y$, a veces implícitamente, a valores como la independencia judicial y separación de poderes, para sostener que los jueces "sólo" están vinculados a la "ley" -independencia judicial $-{ }^{56}$, la cual es creada únicamente por el poder legislativo — separación de poderes $-{ }^{57} \mathrm{y}$, así, justificar mayores posibilidades de apartamiento en general —en donde pueden encontrarse casos de operaciones en las que se derrota un precedente-. Planteándose, además, un dilema entre dichos valores y el principio de igualdad que, mediante la generalidad en la aplicación de la ley, se alcanzaría con el precedente.

En nuestra opinión, los argumentos de la independencia y separación de poderes, tendrían el problema de no tomar en cuenta una de las distinciones más importantes de la cultura jurídica moderna, aquella entre disposición y norma. ${ }^{58}$

Si por "ley" se entiende exclusivamente el texto jurídico emitido por el poder legislativo y que es ese texto el que disciplina las conductas de los ciudadanos, entonces: (i) los precedentes afectan la independencia, pues habría un elemento "distinto" a la ley al que estarían sometidos los

56. Un excelente ejemplo de este argumento es el comunicado que el Consejo Ejecutivo del Poder Judicial publicara en el Diario Oficial "El Peruano", el miércoles 5 de abril de 2006 en la página 15, en pretendida respuesta a la Resolución Jefatural N 021-2006-J-OCMA/PJ, expedida por la Oficina de Control de la Magistratura del Poder Judicial, la cual establecía que todos los órganos jurisdiccionales peruanos, bajo responsabilidad funcional, "den cabal cumplimiento a los precedentes vinculantes señalados por el Tribunal Constitucional".

El comunicado, entonces, replicaría que "Con arreglo a los artículos 138 y 139 inciso 1 de la Constitución y artículo 1 de la Ley Orgánica del Poder Judicial la potestad de administrar justicia se ejerce a exclusividad por el Poder Judicial a través de los órganos jerárquicos conforme a la Constitución y a las leyes (...) Los magistrados judiciales sólo están sometidos a la Constitución y a la ley, y el Estado les garantiza su independencia jurisdiccional, consagrada en el inciso 1 del artículo 146 de la Carta Fundamental y en el artículo 2 de la Ley Orgánica del Poder Judicial"

57. Véase, por ejemplo, en defensa del argumento de separación de poderes Ariano Deho (2006).

58. Para un análisis detallado de esta distinción Cfr. Pozzolo y Escudero (2011). Esta distinción, además, ha sido recogida con utilidad por la Corte Suprema en varias resoluciones —entre ellas: Casación N 17939-2015, 5233-2016 y 21375-2017-, y por el Tribunal Constitucional —entre ellas: Exp. Nº 010-2002-AI/TC, 00013-2017-PI/TC y 000152018-PI/TC-. 
jueces, y (ii) sin duda, el precedente supondría también una superposición en la separación de poderes, pues la potestad exclusiva de crear leyes para disciplinar la conducta de los ciudadanos podría verse sustancialmente afectada por la interpretación contenida en los precedentes.

En cambio, si por "ley" se entiende ya no el texto jurídico, sino la norma que de éste se obtiene mediante la interpretación de las autoridades jurisdiccionales, entonces, el precedente, en tanto especie del género interpretación jurisdiccional, (i) ni afecta la independencia judicial pues seguirlo sería, precisamente, seguir la "ley" resultante de la interpretación decisoria que constituye el precedente, (ii) ni la separación de poderes, pues así entendida la "ley", sería más bien un producto que se obtiene necesariamente del ejercicio conjunto de dos poderes estatales, el legislativo emitiendo el texto y el judicial interpretándolo. Como se evidencia, aplicando la distinción entre disposición y norma, los argumentos de la independencia judicial y separación de poderes, para justificar mayores ámbitos de apartamiento del precedente como la derrota del mismo, resultan muy poco convincentes ${ }^{59} y$, además, el dilema con el principio de igualdad queda disuelto.

Descartados aquellos argumentos jurídicos y valores, quedaría entonces plantearse cuáles serían los otros objetivos o valores que pretenderían realizar aquellos que defienden el otorgamiento a los tribunales inferiores de la potestad de derrotar los precedentes. Quizás, la respuesta de aquellos sería permitir que los tribunales inferiores realicen la "justicia"60 del "caso particular", para lo cual, el precedente sería un obstáculo.

La idea de "justicia formal" ${ }^{\text {, }}$, puede ser satisfactoriamente definida como la exigencia de igualdad, de "que nadie, en forma arbitraria o sin razón suficiente para ello, sea sometido a un trato que difiera del que se acuerda a cualquier otra persona" ${ }^{2}$, lo cual, "no es más que una demanda de que el trato concreto se presente bajo la forma de la aplicación de una regla general (cualquiera sea ésta ${ }^{163}$. Así entendida la justicia, el precedente más bien permite su realización, fortaleciendo institucionalmente la aplicación de una regla general a un mismo caso.

Sin embargo, aquellos defensores parecen estar refiriéndose más bien a la denominada "justicia material", que usualmente es presentada como (i) una entidad "evidente" que se alberga en algún lugar de nuestra conciencia, naturaleza o sociedad, (ii) o como algo que puede conocerse mediante la argumentación racional conforme a ciertos criterios - cánones-y, que además surge como una "necesidad imperativa

59. De hecho, esta no es la única objeción que podría realizarse contra aquellos argumentos. Para un análisis detallado de las tensiones entre precedente, independencia judicial y separación de poderes sugiero revisar Nuñez Vaquero en 2020.

60. Para un análisis detallado sobre el concepto de justicia y sus implicaciones en el razonamiento jurídico en general Cfr. Kelsen (1971).

61. Es mi impresión que, este sentido de justicia es al que se refiere Kelsen cuando concluye en su ensayo "What is justice?", lo siguiente:

"It would have been more than presumptuous to make the reader believe that I could succeed where the most illustrious thinkers have failed. And, indeed, I do not know, and I cannot say what justice is, the absolute justice for which mankind is longing. I must acquiesce in a relative justice and I can only say what justice is to me. Since science is my profession, and hence the most important thing in my life, justice, to me, is that social order under whose protection the search for truth can prosper. "My" justice, then, is the justice of freedom, the justice of peace, the justice of democracythe justice of tolerance."

62. Ross (1958), 263.

63. Ross (1958), 265. 
a priori"164. Pese a ello, en ambos casos, existe un problema epistemológico, pues lo justo ni pertenece al "dominio objetivo"65, ni existe consenso sobre la posibilidad de identificar de manera intersubjetivamente controlable aquellos criterios ${ }^{66}$. Lo cual, haría imposible una discusión racional con quien invoque una pretendida "justicia material".

En otras palabras, ¿Qué es lo justo? ¿Lo justo conforme a qué criterio o parámetro? ¿Según el mérito, según las necesidades, según la capacidad, según el rango y condición -y así sucesivamente- $?^{67}$ ¿y más aún, lo justo para quién? La justicia material, para tener algún contenido necesita precisar estos aspectos y justificar a la luz de sus consecuencias prácticas la elección de algún parámetro. Pues de lo contrario, invocarla no sería más que dar "un golpe sobre la mesa". ${ }^{68}$

Y aún en ese caso, es difícil ver las ventajas de la aplicación de la doctrina de una justicia material al precedente, (i) a nivel de las partes es seguro que la parte derrotada en un litigio, muy difícilmente aceptará que la decisión fue justa "materialmente", (ii) a nivel del sistema, la legitimación de realizar ese tipo de operaciones en oposición a la justicia formal -es decir, en oposición a las exigencias de igualdad entendida como aplicación de una norma general a los mismos casos-, parece tener costos muy altos para la noción occidental del Estado de Derecho, debido al debilitamiento cuando menos de: (ii.1) la seguridad jurídica que se produciría causa de la "mayor indeterminación ex ante" $y$, (ii.2) del elemento democrático a causa de promover el "Derecho" del juez de cada caso -órgano no electo democráticamente- por sobre el "Derecho" de un Estado. Estos costos se asumirían sin tener mayores garantías de alcanzar lo "justo"69, debido a los problemas epistemológicos de aquella empresa, que ya hemos resaltado.

Entonces, que los tribunales inferiores tengan la potestad de derrotar el precedente en atención a la justicia del caso particular, significaría (i) o bien promover la eliminación de la justicia - formal一, (ii) o bien sólo una expresión emotiva sin contenido —el "golpe sobre la mesa"—, (iii) o en el mejor de los casos, una doctrina que parece tener más costos que beneficios, para los individuos y el Estado de Derecho. Quizás por todas estas razones, es que casi la totalidad de los sistemas jurídicos en el mundo no recojan institucionalmente la potestad de los tribunales inferiores de derrotar un precedente. Corresponderá a la judicatura peruana tomar partido en esta cuestión, teniendo en cuenta estos aspectos analizados.

Finalmente, con relación a la operación de overruling, nos parece no es controvertido en nuestra comunidad jurídica que ella se encuentra recogida en el tercer párrafo del artículo 22 de Ley Orgánica del Poder Judicial ${ }^{70}$ y es entendida como una facultad del propio tribunal que estableció el precedente.

64. La frase es de Ross (1958), 266.

65. Como resalta Ratti (2013), 205.

66. Como resalta Comanducci (2016), 97.

67. De hecho, Tarello identifica siete parámetros de justicia distintos utilizados en las sociedades históricas en Tarello (1988), 251 y ss.

68. Ross (1958), 267.

69. Comanducci (2016), 100.

70. Ley Orgánica del Poder Judicial "Carácter vinculante de la doctrina jurisprudencial. Artículo 22.-

Las Salas Especializadas de la Corte Suprema de Justicia de la República ordenan la publicación trimestral en el Diario 


\section{3. ¿Qué parte es vinculante?}

Prima facie, no existe mayor controversia, al menos no la hemos identificado de nuestro estudio, respecto a que la parte vinculante es la establecida explícitamente como PrJ. Las interrogantes que se plantean son más bien: (i) si además del PrJ explícito, también son vinculantes las rationes decidendi de la sentencia; y (ii) si es posible restringir el PrJ explícito, limitándolo sólo a la parte de éste que constituya ratio decidendi.

Esto sin duda, remite nuevamente hacia la noción de ratio decidendi, con todos los problemas que ello supone y que ya hemos desarrollado.

Como advertía en el ejemplo sobre los intereses moratorios de pagos a cuenta, inspirado por la Casación № 4293-2013-Lima, un aplicador que responda afirmativamente a la primera interrogante planteada, si utilizara la noción de ratio decidendi como razón "necesaria", no tendría problema en considerar como tal a cualquiera de las razones que cumplan con dicha propiedad.
Por otro lado, algunos aplicadores del precedente, proclives a responder afirmativamente la segunda interrogante, podrían estar tentados a restringir el alcance del PrJ explícito, a lo que consideren la ratio, es decir sólo a una de las razones necesarias - cualquiera de ellas-. De esa forma, podrían obtenerse resultados como la inaplicación del precedente vinculante al caso concreto o, su aplicación únicamente de ciertos aspectos de éste.

Un buen ejemplo de este tipo de operación, se encuentra en la Sentencia $N^{\circ} 11548-2017$ emitida por una Sala Superior ${ }^{71}$ al afirmar que la Casación № 4293-2013-Lima sólo establece criterios generales de interpretación de normas tributarias -i.e. el criterio que prohíbe la interpretación extensiva y restrictiva de obligaciones y derechos de los contribuyentes-, pero nada sobre la interpretación de las reglas específicas de pagos a cuenta —es decir, nada respecto del artículo 85 de la Ley del Impuesto a la Renta y 34 del Código Tributario-. Valga enfatizar que, en el caso de la Casación $N^{\circ} 4293-$ 2013-Lima el PrJ explícito hace referencia directa a las reglas de pagos a cuenta, por lo que, la argumentación de la Sala Superior se enmarca

Oficial "El Peruano" de las Ejecutorias que fijan principios jurisprudenciales que han de ser de obligatorio cumplimiento, en todas las instancias judiciales.

Estos principios deben ser invocados por los Magistrados de todas las instancias judiciales, cualquiera que sea su especialidad, como precedente de obligatorio cumplimiento. En caso que por excepción decidan apartarse de dicho criterio, están obligados a motivar adecuadamente su resolución dejando constancia del precedente obligatorio que desestiman y de los fundamentos que invocan.

Los fallos de la Corte Suprema de Justicia de la República pueden excepcionalmente apartarse en sus resoluciones jurisdiccionales, de su propio criterio jurisprudencial, motivando debidamente su resolución, lo que debe hacer conocer mediante nuevas publicaciones, también en el Diario Oficial "El Peruano", en cuyo caso debe hacer mención expresa del precedente que deja de ser obligatorio por el nuevo y de los fundamentos que invocan."

71. La Sexta Sala Especializada en lo Contencioso Administrativo con Sub Especialidad en Temas Tributarios y Aduaneros, señaló:

"Este colegiado, concuerda con las reglas determinadas por la Corte Suprema, esto es, que los puntos 5.2.1 y 5.2.2, han sido concebidas en base a los alcances de la Norma VIII del Título Preliminar del Código Tributario; sin embargo, en el ejercicio de sus facultades, analizando los actuados administrativos judiciales, así como las posiciones adoptadas por las partes, llega a la conclusión que existen otros métodos de interpretación de los mencionados textos normativos, a efectos de resolver la presente controversia, como son el literal, sistemático por ubicación de la norma y teleológico, lo que se pasará a examinar."

Se puede evidenciar que la Sala en realidad realiza dos operaciones: (i) reduce el alcance del PrJ de la Casación No 4293-2013-Lima y (ii) luego, simplemente, lo derrota proponiendo "nuevas consideraciones" a las señaladas en el PrJ.

El primer tipo de operación es al que nos referimos en este apartado II.1.3. ¿Qué parte es vinculante? El segundo tipo de operación corresponde al apartado anterior II.1.2. ¿En qué sentido son vinculantes? 
claramente como una operación destinada a restringir el alcance del PrJ explícito.

Ahora bien, lo cierto es que el concepto de ratio decidendi, entendido como razón necesaria, tal como hemos demostrado ${ }^{72}$, es tan amplio que no es posible, al menos no lógicamente, realizar una operación restrictiva, como la realizada por la Sala Superior. Una operación restrictiva como ésa solo es posible mediante un razonamiento que oculte una preferencia, ideología, o doctrina subyacente, la que, precisamente sirva de criterio de selección, es decir, mediante un entimema.

Siendo ése el escenario, conviene recordar lo que sostenía Tarello $^{73}$ para situaciones como esas, en donde el juez tiene que realizar una elección sin más, y por ello, recomienda que esa operación sea "explícita" y "consciente". Debe ser explícita, pues solo de esa forma se asegura el control de la decisión por la comunidad jurídica. Esta exigencia, además, es usualmente entendida como parte de las garantías de debida motivación, en especial, en lo que respecta a la justificación interna, que no permite razonamientos entimemáticos.

$Y$, consciente, es decir que la decisión sea tomada luego de evaluar los "efectos económicos, sociológicos, políticos, (...) como elementos de juicio", "ya que es preferible que los operadores realicen elecciones políticas a la vista de resultados prácticos previstos y deseados, antes de que decidan ciegamente -por ejemplo, en atención a una construcción dogmática elegante- sin representarse con claridad las posibles consecuencias de sus decisiones" 175 . Esta exigencia también puede ser entendida como parte de las garantías de debida motivación, en este caso, en lo que respecta a la justificación externa, que exige la solidez del argumento.

Las sentencias que realicen este tipo de operaciones restrictivas y no cumplan con las exigencias de debida motivación descritas, precisamente por esa razón, podrían ser revocadas por los tribunales superiores.

\section{4. ¿A quiénes vincula?}

No existe controversia de que los PrJ vinculan formalmente a los jueces - sin perjuicio de las operaciones de apartamiento que podrían realizar —ver apartado II.1.2. ¿En qué sentido son vinculantes? - o las de restricción de su alcance - ver apartado II.1.3. ¿Qué parte es vinculante?-. Sin embargo, existen dudas de si también vinculan a la administración pública y sus tribunales: en este caso, a la administración tributaria - SUNAT, Municipalidades, etc. - y Tribunal Fiscal.

Tal como ha señalado el Tribunal Fiscal, el PrJ -refiriéndose al de la Casación No 4293-2013Lima- "sólo resulta vinculante para los órganos jurisdiccionales y no para los administrativos" -Resolución del Tribunal Fiscal No 09516-22016-, más aún "no tiene carácter vinculante para este Tribunal, al no ser dependiente del Poder Judicial" —Resolución del Tribunal Fiscal № 00508-8-2017-. Por ello, que incluso el Tribunal Fiscal haya emitido con fecha posterior a la Casación N 4293-2013-Lima una resolución de "observancia obligatoria", la contenida en la Resolución $N^{\circ}$ 5359-3-2017, en contra de lo señalado en dicha casación.

Las razones pragmáticas usualmente invocadas a favor del precedente ${ }^{76}$, tales como, la

72. Ver apartado II.5. Ratio decidendi y obiter dicta.

73. Según indica Guastini sobre Tarello Guastini (1996), 54.

74. Tarello (1988), 495.

75. Guastini (1996), 54.

76. Sobre estas razones en favor del precedente véase a nivel teórico Núñez Vaquero (2016), 140-154, y a nivel de la dogmática nacional Castillo Córdova (2008), 97, así como el interesante trabajo de Nina Nina y Chancafe Rosas en 2021. 
reducción de los costos - de litigios y de la decisión-y el incremento de la capacidad de orientación del comportamiento que obtiene el ordenamiento jurídico que lo incorpore, así como las razones ideológicas, tales como la mayor realización de la justicia formal y con ello del principio de igualdad, mayor seguridad jurídica debido a la mayor previsibilidad, limitación de la discrecionalidad judicial y administrativa y la realización de la noción de Estado de Derecho; podrían argumentarse, sin problemas, como fundamentos para sostener que el PrJ también debe vincular a los órganos administrativos.

Pero más allá de lo anterior, considero que los argumentos del Tribunal Fiscal para desmarcarse, podrían resultar engañosos cuando menos por lo siguiente:

a) Pues, no toma en cuenta para su análisis lo señalado de manera general por el artículo 384 del Código Civil que establece como fines de la casación: "la uniformidad de la jurisprudencia nacional".

Si esa es una función general del recurso de casación, entonces con mayor razón, debería afirmarse ello del precedente vin- culante regulado en el artículo 36 de la Ley del Procedimiento Contencioso Administrativo.

Asimismo, tampoco introduce en su análisis la regla establecida en la Norma III Código Tributario ${ }^{77}$ que establece a la "jurisprudencia", sin distinguir entre judicial y administrativa, como fuente de derecho, y la regla de jerarquía de fuentes establecidas en el artículo V de la Ley del Procedimiento Administrativo General ${ }^{78}$ que parece privilegiar la jurisprudencia judicial por encima de la emitida por los órganos administrativos.

b) Por otro lado, se estaría realizando, sin explicitarlo, una interpretación evidentemente manipuladora del artículo 36 de la Ley del Procedimiento Contencioso Administrativo.

En efecto, el segundo párrafo de dicho dispositivo señala que los "órganos jurisdiccionales podrán apartarse de lo establecido en el precedente vinculante".

Literalmente, dicho párrafo solo recoge una facultad excepcional de apartamiento

77. Código Tributario:

Norma III: Fuentes del derecho tributario

Son fuentes del Derecho Tributario:

(...)

f) Lajurisprudencia;

g) Las resoluciones de carácter general emitidas por la Administración Tributaria; y,

h) La doctrina jurídica.

78. Ley del Procedimiento Administrativo General:

"Artículo V.- Fuentes del procedimiento administrativo

(...)

2. Son fuentes del procedimiento administrativo:

(...)

2.7. La jurisprudencia proveniente de las autoridades jurisdiccionales que interpreten disposiciones administrativas.

2.8. Las resoluciones emitidas por la Administración a través de sus tribunales o consejos regidos por leyes especiales, estableciendo criterios interpretativos de alcance general y debidamente publicadas. Estas decisiones generan precedente administrativo, agotan la vía administrativa y no pueden ser anuladas en esa sede.

2.9. Los pronunciamientos vinculantes de aquellas entidades facultadas expresamente para absolver consultas sobre la interpretación de normas administrativas que apliquen en su labor, debidamente difundidas.

(...) 
en favor de los órganos jurisdiccionales, es decir, señala que ellos son los únicos que pueden apartarse - "facultad de apartamiento"- . De manera que, con relación al Tribunal Fiscal debería interpretarse que no tienen dicha facultad de apartamiento, por lo cual, se encuentran definitivamente vinculados.

Sin embargo, según el Tribunal Fiscal, de dicho texto debería entenderse más bien que, dado que aquella facultad de apartamiento la tienen sólo los "órganos jurisdiccionales", entonces, por esa razón, sólo a ellos vincula los precedentes y no los órganos administrativos.

No obstante, como es evidente, este segundo resultado interpretativo, solo podría obtenerse en caso se introdujera una norma que señale algo similar a: "los órganos administrativos no están vinculados al precedente judicial". Sin embargo, es muy difícil afirmar que dicha norma se encuentre en el segundo párrafo del artículo 36 de la Ley del Procedimiento Contencioso Administrativo, que como hemos visto, solo recoge una facultad de apartamiento del precedente en favor de los órganos jurisdiccionales y no regula nada sobre qué sujetos, poderes u órganos están vinculados.

c) Por otro lado, tampoco analiza la diferencia entre los distintos sentidos del término jurisdicción y órganos jurisdiccionales.

Es posible diferenciar entre: (i) jurisdicción como aquel poder distinto al poder administrativo, que entre sus funciones se encuentra la de revisar la legalidad de los actos del segundo, y (ii) jurisdicción como la facultad de aplicar derecho de manera institucional. En el primer sentido jurisdicción se identifica con los jueces, mientras que en el segundo se encuentran comprendidos los órganos administrativos que sin duda aplican el derecho y deben motivarlo, ello aun cuando no ostenten jurisdicción en el primer sentido del término.
Si eso es así, es posible interpretar que dentro de la noción de órgano jurisdiccional se encuentran también los órganos administrativos, quienes, a pesar de estar vinculados, también podrían apartarse por ejemplo: mediante el distinguishing-.

Esta diferenciación del término jurisdicción revela su utilidad pues hace viable una conclusión más armonizada del segundo párrafo del artículo 36 y la función uniformadora del recurso de casación, aunque, a la vez, diluye el argumento del Tribunal Fiscal.

d) Finalmente, el argumento del Tribunal Fiscal, se encuentra viciado por la ausencia de diferenciación entre disposición y norma.

Como ya hemos explicado: si por "ley" se entiende ya no el texto jurídico es decir la disposición, sino la norma que se obtiene mediante la interpretación de las autoridades jurisdiccionales, entonces, seguir el precedente vinculante de mayor alcance institucional, como el emitido por la Corte Suprema, es seguir la "ley" misma, hacer lo contrario en cambio sería quebrantarla.

De hecho, el Tribunal Fiscal parece declararse a sí mismo facultado a no observar un "precedente", pero creemos que no estaría inclinado a declarase facultado a no observar la "ley". Ello aun cuando, lo uno y lo otro, signifiquen lo mismo, una vez que se aplica la distinción entre disposición y norma que hemos expuesto.

\section{Precedentes vinculantes del Tribunal Constitucional: jurisprudencia vinculan- te, precedente vinculante.}

Sobre los precedentes vinculantes del Tribunal Constitucional no nos extenderemos como hicimos para el caso de la Corte Suprema, por dos razones. La primera, porque creemos que lo señalado para la Corte Suprema acerca de, el sentido en que son vinculantes sus precedentes, en especial lo analizado sobre la derrotabilidad 
de los mismos - Il.1.2 - el alcance del precedente, en especial su vinculación con la noción de ratio decidendi - Il.1.3-, podría aplicarse, sin mucha dificultad, al caso del Tribunal Constitucional. La segunda, porque sobre el precedente del Tribunal Constitucional la dogmática nacional ha sido bastante más prolíica, por lo que nos parece un interesante ejercicio dejar al lector aplicar los conceptos desarrollados en este trabajo como herramientas de contraste o análisis de aquella. ${ }^{79}$

Entonces, sólo quisiéramos restringir nuestros comentarios a una interrogante particular ¿Cuáles de las interpretaciones del Tribunal Constitucional son vinculantes en sentido formal?

Parece no existe controversia en reconocer tres resultados vinculantes del Tribunal Constitucional, estos serían, cuando menos: el derivado de los procesos de inconstitucionalidad - segundo párrafo del artículo VI del Código Procesal Constitucional-, el denominado precedente vinculante constitucional: "PV" —artículo VII del Código Procesal Constitucional-y la denominada jurisprudencia constitucional vinculante o doctrina jurisprudencial: "JV" —-tercer párrafo del artículo VI del Código Procesal Constitucional-.$^{80}$

Ya hemos señalado también, que la posición mayoritaria en la doctrina ${ }^{81}$, se inclina por considerar al PV y JV vinculantes en el mismo sentido, aunque la diferencia sería que en el primero la ratio decidendi debe ser explicitada por el Tribunal Constitucional -ratio decidendi explicita- $y$ en el segundo corresponde al aplicador identificar la ratio decidendi vinculante - ratio decidendi implícita-. Cabe precisar que, no vemos una necesidad conceptual de que la JV sea "reiterada" o requiera constituir una "tendencia", de forma que solo así adquiera su carácter vinculante. ${ }^{82} \mathrm{Y}$, de hecho, el tercer párrafo del artículo VI del Código Procesal Constitucional, tampoco lo exige expresamente.

En la misma línea, el Tribunal Constitucional ha justificado la vinculatoriedad de sus interpre-

79. Nos referimos fundamentalmente a Castillo Córdova (2008), Carpio Marcos y Grández Castro (2007), el conocido trabajo de Landa Arroyo (2010), y, para un análisis detallado sobre las reglas de producción del precedente López Flores (2016).

80. No analizaremos la vinculación de facto, pues ello ameritaría otro de tipo de investigación sociológica y psicológica incluso, que se encuentra fuera de nuestro alcance, por supuesto.

81. En mayoría Rodríguez Santander (2007), 59, Grández Castro (2007), 94-95, López Flores (2016) e incluso en la formulación algo confusa de Castillo Córdova (2008).

Una posición contraria, es sostenida por Landa Arroyo en 2010 quien propone que existen por los menos tres grados distintos de vinculación. Nos parece que la propuesta de Landa, no diferencia entre vinculación formal y de facto, por lo que su propuesta de grados de vinculación incurre en la misma imprecisión que Interpreting Precedents.

82. Contrariamente a lo señalado por Rodríguez Santander (2007), 59 y Grández Castro (2007), 94-95.

83. Expediente № 03950-2012-PA/TC:

"Queda claro para este Tribunal que el principio de predictibilidad y certeza de las decisiones judiciales se ve seriamente afectado, siendo no menos evidente la afectación del derecho a la igualdad en la aplicación del derecho allí donde en el lento jurídico se producen dos o más interpretaciones dispares (que en son forzadas, distorsionadas y antojadizas) en torno al sentido de la doctrina jurisprudencial del Tribunal Constitucional, establecida en virtud del artículo VI del Título Preliminar del Código Procesal Constitucional y la Primera Disposición Final de la Ley 28301, Orgánica del Tribunal Constitucional, o simplemente, cuando se omite o inobserva deliberadamente la aplicación de dicha doctrina jurisprudencial. En consecuencia, en situaciones en las cuales el principio de seguridad jurídica se vea afectado por la existencia de una disparidad de criterios interpretativos en torno al sentido de la doctrina jurisprudencial o se produzca la inaplicación de la misma, este Tribunal está llamado a reparar dicha afectación, pues así lo exige no sólo el mencio- 
taciones según el artículo VI del Código Procesal Constitucional, en función a los principios de predictibilidad y certeza de las decisiones judiciales, seguridad jurídica y su "supremacía interpretativa", concluyendo por todo ello, en la necesidad de que sus interpretaciones sean vinculantes a "todo poder público"83.

Pese a la aparente posición mayoritaria en la doctrina y lo señalado por el Tribunal Constitucional, cabe analizar si podrían existir razones para realizar una construcción normativa del tercer párrafo del artículo VI del Código Procesal Constitucional restrictiva o reductiva de la vinculatoriedad de la JV. Es decir, una construcción en el sentido que dicho dispositivo, aun cuando no lo dice su texto ${ }^{84}$, se refiere: (i) o sólo a la vinculatoriedad de las interpretaciones contenidas en los PV, (ii) o a una vinculación de menor "grado". 85

Pero, ¿cuáles serían los valores que pretenderían realizarse mediante esa reducción del alcance del precedente? ¿Serían los valores de independencia judicial, separación de poderes, justicia material? Aquellos que, según ya hemos analizado ${ }^{86}$, no resultan convincentes para ese fin reductivo. Nos parece, entonces que lo anterior no podrá solucionarse con referencias o citas genéricas a dichos valores, sino que, de nuevo, debería tratarse de un decisión explícita y consciente, tal como exige el principio de debida motivación.

En tanto decisión consciente, por supuesto, deberá ser evaluada a la "vista de resultados prácticos" —por ejemplo: el impacto en los costos de litigio y decisión, el incremento o no de la función orientación del comportamiento, entre otros factores- y no decidir "ciegamente en atención a una construcción dogmática elegante". Una construcción normativa que "reduzca" el alcance del tercer párrafo del artículo VI del Código Procesal Constitucional y, con ello el alcance general de la regla del stare decisis en el país, sólo podría estar justificada de manera sólida, en la medida que ello sea soportado en función a los resultados prácticos que se espera deriven de aquella.

nado principio constitucional, sino también la supremacía interpretativa que ostenta este Colegiado.

De otra parte, no escapa a la consideración de este Tribunal que, si bien es cierto que las sentencias expedidas por este Tribunal en los procesos de tutela de derechos no pueden invalidar retroactivamente las interpretaciones de otros poderes públicos que, no obstante ser disconformes con las interpretaciones vinculantes establecidas en aquélla, ostenten la calidad de cosa juzgada, no lo es menos que, en virtud del artículo VI del Título Preliminar del Código Procesal Constitucional y la Primera Disposición Final de la Ley 28301, Orgánica del Tribunal Constitucional, antes reseñadas, las sentencias expedidas por este Tribunal en el marco de tales procesos, en razón de su efecto vinculante, generan la obligación inmediata de todo poder público de inaplicar las decisiones de otro órgano estatal que representen una interpretación contraria a los criterios establecidos en las sentencias del Tribunal Constitucional."

84. Recuérdese que dicho dispositivo señala:

"Artículo Vl.- Control Difuso e Interpretación Constitucional

(...)

Los Jueces interpretan y aplican las leyes o toda norma con rango de ley y los reglamentos según los preceptos y principios constitucionales, conforme a la interpretación de los mismos que resulte de las resoluciones dictadas por el Tribunal Constitucional."

Es decir, no establece ninguna de las "reducciones" o "restricciones" que analizaremos a continuación.

85. Como se expresa en Landa Arroyo (2010), y que ya hemos advertido es un planteamiento que se encuentra viciado, pues no advierte que antes que "grados" de vinculación, sus categorías se refieren a distintos "sentidos" de vinculación, los cuales no pueden "graduarse" pues se ubican en distintos planos. Ver apartado II. 4. Fuerza vinculante y fuerza justificante.

86. Ver apartado I.1.2. ¿En qué sentido son vinculantes? 


\section{Bibliografía}

Alchourrón, C. y Bulygin, E. 1975. Sistemas normativos (Segunda ed. 2017). Buenos Aires: Astrea

Alchourrón, C. y Bulygin, E. 1991. Análisis lógico y derecho. Madrid: Centro de Estudios Constitucionales.

Ariano Deho, E. 2006. Precedentes vinculantes y pirámide normativa. Los frenesíes del Poder del Tribunal Constitucional. 75-90. Diálogo con la Jurisprudencia.

Arraigada Cáceres, M. 2017. “Normas de competencia y normas acerca de la competencia. Eludiendo las reglas constitutivas", DOXA, 93-121.

Atienza, M. y Ruiz Manero, J. 2000. Ilícitos atípicos. Madrid: Trotta.

Caracciolo, R. 2009. El derecho desde la filosofía. Madrid: Centro de Estudios Políticos y Constitucionales.

Carpio Marcos, E. y Grández Castro, P. 2007. Estudios al precedente constitucional. Lima: Editorial Palestra.

Castillo Córdova, L. 2008. El tribunal constitucional peruano y su dinámica jurisprudencial. México: Porrúa.

Castillo Córdova, L. 2008. El Tribunal Constitucional peruano y su dinámica jurisprudencial. Lima: Editorial Palestra.

Chiassoni, P. 2007. Técnicas de interpretación jurídica: brevario para juristas (2011). Madrid: Marcial Pons.

Chiassoni, P. 2018. Ensayos de metajurisprudencia analítica. México: Derecho Global.

Chiassoni, P. 2019. Interpretation without truth: A realistic enquiry. Cham-Switzerland: Springer.

Comanducci, P. 1999. Razonamiento Jurídico. Elementos para un modelo (Segunda reimpresión ed. 2009). México: Fontanamara.

Comanducci, P. 2016. Apuntes sobre la teoría del Derecho contemporánea (Ed. 2018). México: Derecho Global.

Ferrer Beltrán, J. 2000. Las normas de competencia. Un aspecto de dinámica jurídica. Madrid: Centro de Estudios Políticos y Constitucionales.

Ferrer Beltrán, J. 2007. La valoración racional de la prueba. Madrid: Marcial Pons.

Ferrer Beltrán, J. 2018. Prolegómenos para una teoría sobre los estándares de prueba. En D. Papayannis, y E. Pereira Fredes, Filosofía del derecho privado. 402-430. Madrid: Marcial Pons.

Gascón Abellán, M., y García Figueroa, A. 2003. La argumentación en el derecho. Algunas cuestiones fundamentales. Lima: Editorial Palestra. 
Grández Castro, P. 2007. Peculiaridades del precedente constitucional en el Perú. En E. Carpio Marcos, y P. Grández Castro, Estudios al precedente constitucional. 79-106. Lima: Palestra.

Guastini, R. 1996. Distinguiendo. Estudios de teoría y metateoría del derecho (1999). Barcelona: Gedisa.

Guastini, R. 2010. Las fuentes del derecho. Fundamentos teóricos (Segunda ed. 2017). Lima: Legales Ediciones.

Guastini, R. 2011. Interpretar y argumentar (Segunda ed. 2018). Madrid: Centro de Estudio Políticos y Constitucionales.

Guastini, R. 2014. Otras distinciones. Bogotá: Universidad Externado de Colombia.

Guastini, R. 2014. Realismo jurídico redefinido. En R. Guastini, Otras distinciones, 337-367. Bogotá: Universidad Externado de Colombia.

Guastini, R. 2016. La sintaxis del derecho. Madrid: Marcial Pons.

Guibourg, R. 1999. Pensar en las normas (2016). Buenos Aires: Eudeba.

Kelsen, H. 1971. What is justice? Justice, Law, and Politics in the mirror of science. Los Angeles: University of California Press.

Landa Arroyo, C. Los precedentes constitucionales: el caso del Perú. Anuario Iberoamericano de Justicia Constitucional (2010): 193-234

López Flores, L. "¿Interpretaciones no vinculantes de un 'supremo interprete' reflexiones sobre el rol del Tribunal Constitucional peruano a propósito de una reciente modificación de su reglamento normativo". VOX JURIS (2016): 59-70.

MacCormick, N., y Summers, R. 1997. Interpreting Precedents (2016). New York: Routledge.

Mendonca, D. 1992. Introducción al análisis normativo. Madrid: Centro de Estudios Constitucionales.

Nina Nina, P., y Chancafe Rosas, D. El precedente tributario como instrumento para evitar el inicio de procesos repetitivos en el Perú. En F. Nuñez del Prado, y L. Ghersi Murillo, Justicia de Papel. Reformas disruptivas al sistema de justicia. Lima: Palestra, 2021: 509-531

Núñez Vaquero, Á. 2016. Sin precedentes: una mirada escéptica a la regla del stare decisis. Alicante: DOXA.

Núñez Vaquero, Á. “Precedente en materia de hechos", Revista de Derecho Valdivia (2018): 51-78.

Nuñez Vaquero, Á. "¿Violan los precedentes la IJI? Desencuentros", Revista Derecho PUCP (2020), 303-336. 
Pozzolo, S., y Escudero, R. 2011. Disposición vs. Norma. Lima: Palestra.

Ratti, G. B. 2013. El gobierno de las normas. Madrid: Marcial Pons.

Ratti, G. B. Un poco de realismo sobre inconstitucionalidad y derogación. Discusiones XIV (2014): 253-276.

Redondo, M. C. Sobre la justificación de la sentencia judicial. En M. Redondo, J. Sauca, y P. Ibáñez, Estado de Derecho y decisiones judiciales. Madrid: Fundación Coloquio Jurídico Europeo, 2009: 63-100.

Rodríguez Santander, R. El precedente constitucional en el Perú: Entre el poder de la historia. En E. Carpio Marcos, y P. Grández Castro, Estudios al precedente constitucional. Lima: Palestra, 2007: 15-78

Ross, A. 1958. Sobre el Derecho y la Justicia (1963 ed.). Buenos Aires: Eudeba.

Schauer, F. 2009. Thinking like a lawyer. A new introduction to legal reasoning. Harvard University Press.

Tarello, G. 1980. trad. L'interpretazione della legge, Milano, Dott. A. Giuffrè Editore, 1980. La interpretación de la Ley (2013). Lima: Palestra.

Tarello, G. 1988. Cultura jurídica y Politica del derecho (2002 ed.). Granada: Comares.

Taruffo, M. 1975. La motivación de la sentencia civil (2011). Madrid: Trotta.

Taruffo, M. “Consideraciones sobre el Precedente", IUS ET VERITAS (2016): 330-342.

Wróblewsky, J. “Legal Syllogism and Rationality of Judicial Decision”, Rechtstheorie (1974): 33-46 